\title{
Kinetics of Microbial Production of 2, 3-Butanediol from Cheese Whey Using Klebsiella pneumonia
}

\author{
Azeez Taofik Oladimeji
}

\begin{abstract}
In the light of limitation arising from the expensive nature of the production of 2,3-Butanediol (2,3-BD) from competitive petrochemical products and treatment of cheese whey based on biochemical oxygen demand (BOD) posed to the environment. The effect of aerated condition, $\mathrm{pH}$, initial concentration of the cheese whey was studied with an aim to provide insight into optimal conditions for maximum bioremediation as an attractive alternative for cheese whey treatment and production of 2,3-BD using Klebsiella pneumonia (KP) at room temperature of $28^{\circ} \mathrm{C}$ for $96 \mathrm{~h}$ and kinetics parameters were evaluated from the experimental result. Based on the result of the proximate analysis, lactose content in $40 \mathrm{~g} / \mathrm{l}$ of cheese whey produced 61.3 percent of 2,3-BD at an optimum $\mathrm{pH}$ value of 6.40 and 36.6 percent of 2,3-BD at an optimum $\mathrm{pH}$ value of 6.46 in an air-stirred batch reactor and unstirred batch reactor respectively while lactose content in $20 \mathrm{~g} / \mathrm{l}$ of cheese whey produced 60.9 percent $2,3-\mathrm{BD}$ at an optimum pH value of 5.92 and 29.2 percent of 2,3-BD at an optimum pH value of 6.14 in an air-stirred batch reactor and unstirred batch reactor respectively. The result shows that Klebsiella pneumonia has good bioremediation potential and production of 2,3-BD in air-stirred batch reactor compared to unstirred batch reactor at room temperature of $28^{\circ} \mathrm{C}$ under optimum pH value and initial concentration of lactose content in cheese whey.
\end{abstract}

Index Terms-Bioremediation, Cheese whey, Klebsiella pneumonia, Monod's model and Malthus correlation.

\section{INTRODUCTION}

Cheese whey, the greenish translucent liquid is a major by-product of dairy industry obtained by application of acid, heat and rennet after milk coagulation and removal of the curd. It contains large percentage of lactose as well as moieties of protein, fat and mineral salts [1].

Whey has been viewed as one of the major disposal problems of the dairy industry because of the high volumes produced of organic matter such as lactose which responsible for high chemical oxygen demand (COD) and biochemical oxygen demand (BOD) that indicates high pollution potential [2]-[6].

In many countries including India, most of the cheese whey usually discarded as waste creating severe environmental pollution problems due to its high COD and BOD [7]. This necessity has been heightened, in recent years, by the increased volume of cheese whey being produced. Cheese whey has been treated by means of a coagulation-flocculation process by the application of coagulants $\mathrm{FeSO}_{4}, \mathrm{Al}_{2}\left(\mathrm{SO}_{4}\right)_{3}$, and $\mathrm{FeCl}_{3}$ depending upon

Manuscript received June 3, 2011; revised August 28, 2011.

T. O. Azeez is with Biomedical Technology Department, School of Health Technology, Federal University of Technology, P. M. B. 1526, Owerri, Nigeria. (Phone No.: +234(0)8035996137; e-mail: thaophic@yahoo.com) operating conditions on the basis of experimental results of sedimentation tank design for the treatment of COD and BOD respectively [8]. However, effluents coming from the coagulation-flocculation pre-stage necessitate half of the time required by the non-pretreated raw [3], [8]-[10].

The use of lactose in biotechnological processes reduces the BOD level posed by cheese whey [6]. In order to reduce the BOD level and acquire useful compounds, the cheese whey can be used as a cheap source of food and energy for the valuable products by microbes [3], [10]-[14]. Biological systems, either aerobic or anaerobic can be used in the treatment of whey based on the microbes used, availability and product formation [2], [3], [12]. However, anaerobic digestion offers advantages over aerobic process, especially in the production of toxic products from cheese whey [8]-[10]. Though, aerobic biodegradation of cheese whey achieves a higher degree of the reduction of the main contaminant indicators of COD and BOD compared with anaerobic biodegradation [8], [10]. A number of options have been proposed to convert permeate to value added products and other more profitable alternatives [1]-[3], [10]-[12], [14], one of which is production of potentially value added chemical 2,3-BD having diverse applications in chemical industries. Many researchers work on the production of 2,3-BD and its immediate precursor has centered around the microorganisms such as Klebsiella oxytoca, Klebsiella pneumonia, Bacillus polymyxa, Enterobacter aerogenes etc. [14]-[19], [22] and on the utilization of inexpensive substrates majorly whey [15], [22], [23]. The main constraint in the commercialization of 2,3-BD production is its economic recovery from fermentation broth due to its high boiling point, great affinity with water [3], [12] and kinetics of cheese whey degradation by the activity of the klebsiella pneumonia. Thus efficient large scale recovery processes through bioremediation as a cheap alternative means with potential for continuous operation should be considered and developed so as to overcome this environmental problem based on the high content of lactose.

The objective of this work is to obtain quantitative insight into kinetics of degradation of klebsiella pneumonia as a basis for bioremediation of threat posed by the cheese whey as a cheap fermentative feedstock for production of 2,3-BD for healthy and safety of the environment. Determine the favourable conditions for bioremediation of the cheese whey with aids of evaluated kinetics parameters and effect of 2 , $3-\mathrm{BD}$ on the observed growth rate of klebsiella pneumonia.

\section{MATERIALS AND METHOD}

\section{A. Proximate Analysis of Cheese Whey}

Cheese whey was obtained from a local cheese making 
industry and was characterized for its composition. The method of Khanaferi and Sepahei (2007) [23] was used to determined lactose, proteins and fats content. Ashes were determined by sample incineration at $450^{\circ} \mathrm{C}$ and expressed as carbonates [24]

\section{B. Determination of Mass Concentration of Klebsiella Pneumonia and 2,3-Butanediol}

Culture of KP was obtained from Medical Laboratory, Bowen University of Teaching Hospital, Ogbomoso tagged in a slide. Cheese whey broth samples A contains $40 \mathrm{~g} / \mathrm{L}$ and B contains $20 \mathrm{~g} / \mathrm{L}$ were prepared at different concentration, boiled, filtered and oil content was removed and discarded. $150 \mathrm{ml}$ of each of the whey broth measured as $A_{1}, A_{2}, B_{1}$ and $\mathrm{B}_{2}$ were autoclaved at $121^{\circ} \mathrm{C}$ and 15 psia for 15 minutes. KP was inoculated into the nutrient agar plates for production of the bacterium enmasse for 24hours and inoculated into $A_{1}, A_{2}$, $\mathrm{B}_{1}$ and $\mathrm{B}_{2}$ at $28^{\circ} \mathrm{C}$ for $96 \mathrm{~h}$. $\mathrm{A}_{1}$ and $\mathrm{B}_{1}$ were air-stirred batch reactors while $A_{2}$ and $B_{2}$ were unaerated batch reactors. Samples were taken at every 12 hours to determine microbial mass concentration of KP. The dry weight analysis method was used to determine microbial mass concentration of KP in which $10 \mathrm{ml}$ of each of sample of $\mathrm{A}_{1}, \mathrm{~A}_{2}, \mathrm{~B}_{1}$, and $\mathrm{B}_{2}$ were taken every12hours and centrifuged at a 2500 rpm for every 20minutes. The supernatant was decanted into a glass container and KP cells that settled down at the bottom of the centrifuge tube were scooped and dried in an oven at a temperature of $60^{\circ} \mathrm{C}$ for 8 hours to a constant weight and recorded. The weight obtained was taken as the dry weight of $\mathrm{KP}$ in the sample analyzed. The procedure of Desnuelle and Naudet method (1945) [19], [21] was employed for chemical assay of 2, 3-BD in supernatant using spectrophotometer.

\section{C. $p H$ Value of the spent medium}

The $\mathrm{pH}$ meter (Hannan H18579 model) was standardized with standard buffers of $\mathrm{pH} 4.0,7.0$ and 9.0 after which the $\mathrm{pH}$ of the samples were measured and recorded.

\section{Isolation of 2,3-Butanediol}

The method of Akinobu et al, 1992 [25] was employed to isolate 2, 3-BD and $\mathrm{KP}$ cells from spent medium by centrifugation as earlier described. The supernatant were separated from the cells and $5 \mathrm{ml}$ of each of supernatant of sample $A_{1}, A_{2}, B_{1}$, and $B_{2}$ was saturated with sodium chloride salt and 2, 3-BD was extracted from saturated supernatant with ethyacetate of equal volume. The ethylacetate layer was separated from aqueous layer by separating funnel, and then dehydrated with anhydrous Glauber's salt and 2, 3-BD with colourless, transparent, sharp taste and syrup in nature was removed under reduced pressure.

\section{MATHEMAtics OF Kinetics Of CELl GROWTH AND RODUCTION 2, 3-BD}

The model is based on the stoichiometry equation (1) with theoretical frame work that it is design for both air-stirred and unaerated batch reactors. The reaction rate for both Microbes formation, cheese whey and 2,3-BD produced are of first order reaction as expressed as:

$$
\text { Cheese whey } \stackrel{\mathrm{KP}}{\rightarrow} 2,3 B D+\mathrm{KP}(\text { enmasse })
$$

\section{A. Yield of 2, 3-BD relative to lactose utilization.}

The rate of formation of 2,3-BD due to degradation was based on the rate of consumption of lactose utilization by KP $[26,27]$.

$$
\frac{\partial C_{B D}}{\partial t}=Y_{B D / L}\left(-\frac{\partial C_{L}}{\partial t}\right)
$$

$\frac{\partial C_{B D}}{\partial t}$ is the rate of formation of 2,3-Butanediol, $\frac{\partial C_{L}}{\partial t}$ is the rate of appearance of lactose utilization and $Y_{B D / L}$ is the yield of 2, 3 -BD relative to lactose utilization. The negative sign (-) indicates that an increased concentration of KP and 2,3-BD produced were accomplished by a decreased in concentration of lactose utilization in cheese whey. The magnitude of yield of 2,3-BD relative to lactose utilization can be expressed as (3) below:

$$
Y_{B D / L}=\frac{\text { Mass Concentration of 2,3-butanediol produced }}{\text { Mass Concentration of Lactose without lipid content }}
$$

B. Yield of KP cells relative to 2,3-BD formation.

The rate of formation of the Klebsiella pneumonia is a function of rate of production of 2, 3-BD expressed as:

$$
\frac{\partial X}{\partial t}=Y_{X / B D} \frac{\partial C_{B D}}{\partial t}
$$

Integrate equation (4) with boundary conditions: $C_{B D}=C_{B D 0}$ when $X=X_{0}$ and $C_{B D}=C_{B D}$ when $X=X$ Equation (4) becomes

$$
X-X_{0}=Y_{X / B D}\left(C_{B D}-C_{B D 0}\right)
$$

$Y_{X / B D}$ is the yield of KP relative to 2,3-BD formation, $X$ is mass concentration of $\mathrm{KP}(\mathrm{mg} / \mathrm{l})$ at any time $\mathrm{t}, X_{0}$ is the mass concentration of $\mathrm{KP}(\mathrm{mg} / \mathrm{l})$ at time $\mathrm{t}=0 . C_{B D}$ is the mass concentration of $2,3-\mathrm{BD}(\mathrm{g} / \mathrm{l})$ at any time $\mathrm{t}=\mathrm{t}$ and $C_{B D 0}$ is the mass concentration of 2,3-BD $(\mathrm{g} / \mathrm{l})$ at time $\mathrm{t}=0$. Yield of $\mathrm{KP}$ cells relative to 2,3-BD formation was obtained by simulation of equation (5) as shown in the figure 3-6.

\section{Yield of KP relative to the lactose utilization.}

Concentration of the lactose utilization as a spent medium at any time $\mathrm{t}$ can be quantified from equation (6) which obtained after integration (2) as thus;

$$
C_{L}=C_{L 0}-\frac{\left(C_{B D}-C_{B D 0}\right)}{Y_{B D / L}}
$$

$C_{L}$ is the mass concentration of Lactose utilization $(\mathrm{g} / \mathrm{l})$ at any time t and $C_{L 0}$ is the initial mass concentration of Lactose utilization $(\mathrm{g} / \mathrm{l})$ at time $\mathrm{t}=0$.

Reaction rate of Klebsiella pneumonia formation is proportional to the rate of disappearance of lactose utilization as a source of food and energy for the Klebsiella pneumonia $[21,[22]$.

$$
\frac{\partial X}{\partial t}=Y_{X / L}\left(-\frac{\partial C_{L}}{\partial t}\right)
$$

$\frac{\partial X}{\partial t}$ is the rate of formation of $\mathrm{KP}$ enmasse and $Y_{X / L}$ is the yield of KP relative to the lactose utilization.

Combine equations 2, 3 and 4 gives 


$$
Y_{X / L}=Y_{B D / L} x Y_{X / B D}
$$

Equation (8) is the yield of KP cells relative to the lactose utilization as shown in the table 3.

\section{Maximum Specific Growth Rate and Monod's Kinetics Constant.}

The biodegradation of lactose utilization is limited to the growth of the KP cells following the concept of Malthus correlation, first order reaction rate and Monods kinetics model based on the limit lactose concentration. The growth rate of Klebsiella pneumonia is given by Malthus model expressed as equation 9:

$$
\frac{\partial X}{\partial t}=\mu_{o b s} X
$$

The observed growth rate based on the concentration of the limiting lactose utilization and it is governed by Monod's expression as given in equation 10 ;

$$
\mu_{o b s}=\mu_{m} \frac{C_{L}}{k_{S}+C_{L}}
$$

$\mu_{o b s}$ is the observed specific growth rate, $\mu_{m}$ is the maximum specific growth rate and $k_{s}$ is the Monod's kinetics constant.

Combination of equations 9 and 10 gives

$$
\frac{1}{X}\left(\frac{\partial X}{\partial t}\right)=\mu_{m} \frac{C_{L}}{k_{S}+C_{L}}
$$

Linearization of equation 11 gives

$$
t=\frac{1}{\left\{\frac{1}{X}\left(\frac{\partial X}{\partial t}\right)\right\}}=\frac{k_{s}}{\mu_{m}}\left(\frac{1}{C_{L}}\right)+\frac{1}{\mu_{m}}
$$

Equation (12) was used for determination of $\mu_{m}$ as the reciprocal of an intercept of the tread curve and $k_{s}$ as a product of the slope of the curve and the evaluated value of $\mu_{m}$ [26] as shows in the figure 7-10. The magnitude of kinetics parameters $Y_{B D / L} \quad Y_{X / L} \quad \mu_{m}$, and $k_{s}$ indicate the favourable conditions of the bioremediation of the cheese whey and production of 2, 3-BD for $96 \mathrm{~h}$ at room temperature.

\section{RESUlTS AND DiscUSSIONS}

The compositions of the content of cheese whey used from the analysis in this study were shown in the table 1 as the proximate analysis of the local cheese whey.

Figure 1 shows the mass concentration of KP during $96 \mathrm{~h}$ of fermentation and Figure 2 shows mass concentration of lactose utilization and 2,3-BD during fermentation time of 96h. It can be deduced from the the figure 1 and 2 that the rate of production of 2,3-BD increased as result of decreased in the rate of depletion or disappearance of lactose concentration by the activity of the KP. Here lactose concentration and the lower concentration of the microbes in the whey used in the study might be one of the reasons of lower product concentration [14]. $\mathrm{m}, \mathrm{g}$ and L refers to klebsiella pneumonia, 2,3-BD and lactose in the Figure 1 and 2.

TABLE 1. Proximate ANALysis of Local CHEESE Whey USED

\begin{tabular}{lc}
\hline Composition & Approximate Content $(\mathrm{w} / \mathrm{w})$ \\
\hline Protein & 12.90 \\
Fat and Oil & 2.10 \\
Ash & 7.95 \\
Water & 4.54 \\
Lactose & 72.50 \\
\hline
\end{tabular}

Table 2 shows that $\mathrm{pH}$ value of the spent medium of the production of 2,3-BD in both unstirred $\left(\mathrm{A}_{1}\right.$ and $\left.\mathrm{B}_{1}\right)$ and air-stirred $\left(A_{2}\right.$ and $\left.B_{2}\right)$ batch reactors. The rises in the $\mathrm{pH}$ values of the spent medium for $A_{1}, A_{2}, B_{1}$ and $B_{2}$ rises from $6.50,6.50,6.69$ and 6.69 to $7.02,6.59,8.10$ and 6.85 during fermentation period of 48 hours could be attributed to the adaptation of KP cells and production of 2,3-Butanediol without adverse effect on the yield of KP cells and later fall gradually to optimum values of $6.40,6.46,5.92$ and 6.14 respectively which indicates that there have been a production of 2, 3-BD and growth of KP cells in the cheese whey broths. The simulated yield value of the KP during 2, 3-BD production for sample $A_{1}, A_{2}, B_{1}$ and $B_{2}$ can be shown in the Figure 3-6. The magnitude of $R^{2}$ as shows in each of the curve indicates the degree of fitness of the experimental result with equation 5 .

TABLE 2. PH VALUE OF THE SPENT MEDIUM

\begin{tabular}{cllll}
\hline Time (hr) & \multicolumn{3}{c}{$\mathrm{pH}$} \\
& $\mathrm{A}_{1}$ & $\mathrm{~A}_{2}$ & $\mathrm{~B}_{1}$ & $\mathrm{~B} 2$ \\
\hline 0 & 6.50 & 6.50 & 6.69 & 6.69 \\
12 & 6.64 & 6.53 & 7.05 & 6.74 \\
24 & 6.76 & 6.55 & 7.40 & 6.77 \\
36 & 6.89 & 6.57 & 7.75 & 6.81 \\
48 & 7.02 & 6.59 & 8.10 & 6.85 \\
60 & 6.95 & 6.55 & 7.30 & 6.76 \\
72 & 6.89 & 6.52 & 6.45 & 6.67 \\
84 & 6.64 & 6.49 & 6.19 & 6.40 \\
96 & 6.40 & 6.46 & 5.92 & 6.14 \\
\hline
\end{tabular}



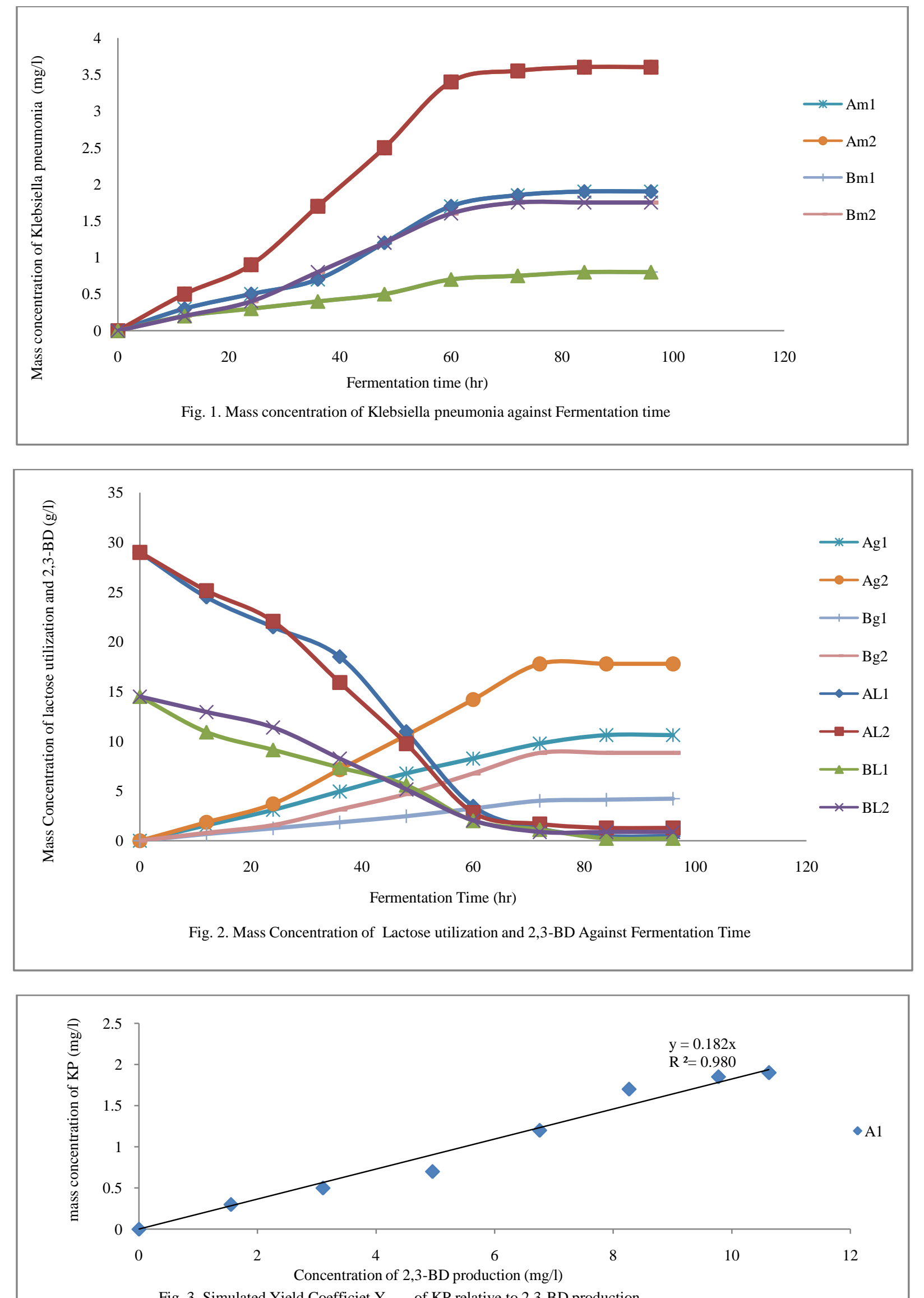

Fig. 3. Simulated Yield Coefficiet $\mathrm{Y}_{\mathrm{X} / \mathrm{BD}}$ of KP relative to 2,3-BD production 

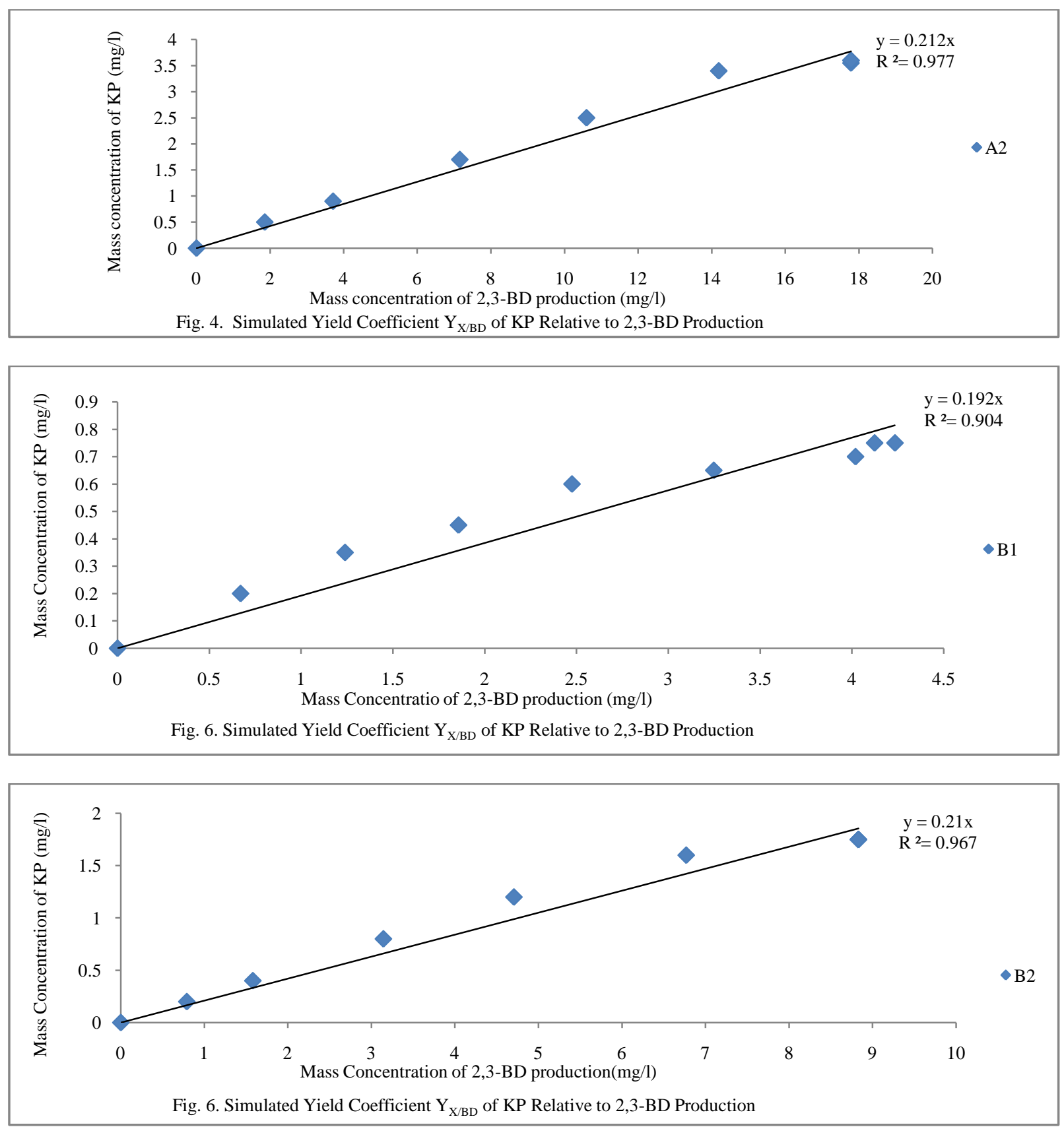

Figure 7-10 depict the simulated maximum specific growth rate $\mu_{\mathrm{m}}$ and Monod's kinetics constant $\mathrm{k}_{\mathrm{s}}$ of KP relative to the lactose utilization based on equation (12) and yield coefficient $Y_{\mathrm{X} / \mathrm{L}}$ of 2, 3-BD relative to lactose utilization

was quantified using equation (5). The degree of the fitness of the result data with equation 5 was shown the magnitude of the figure $7-10$.

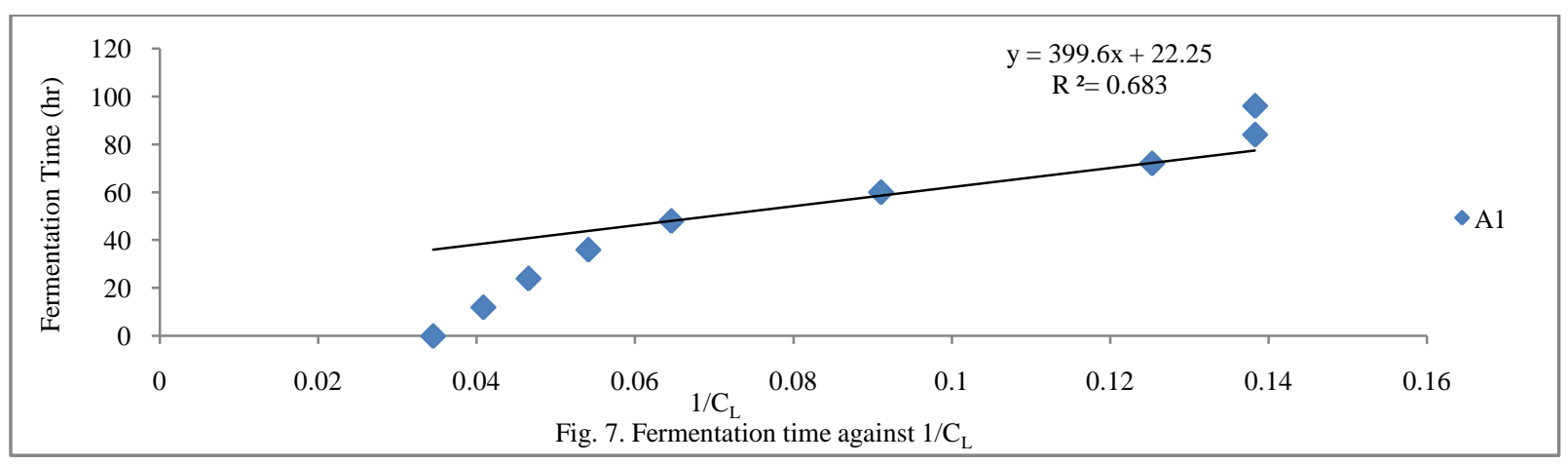



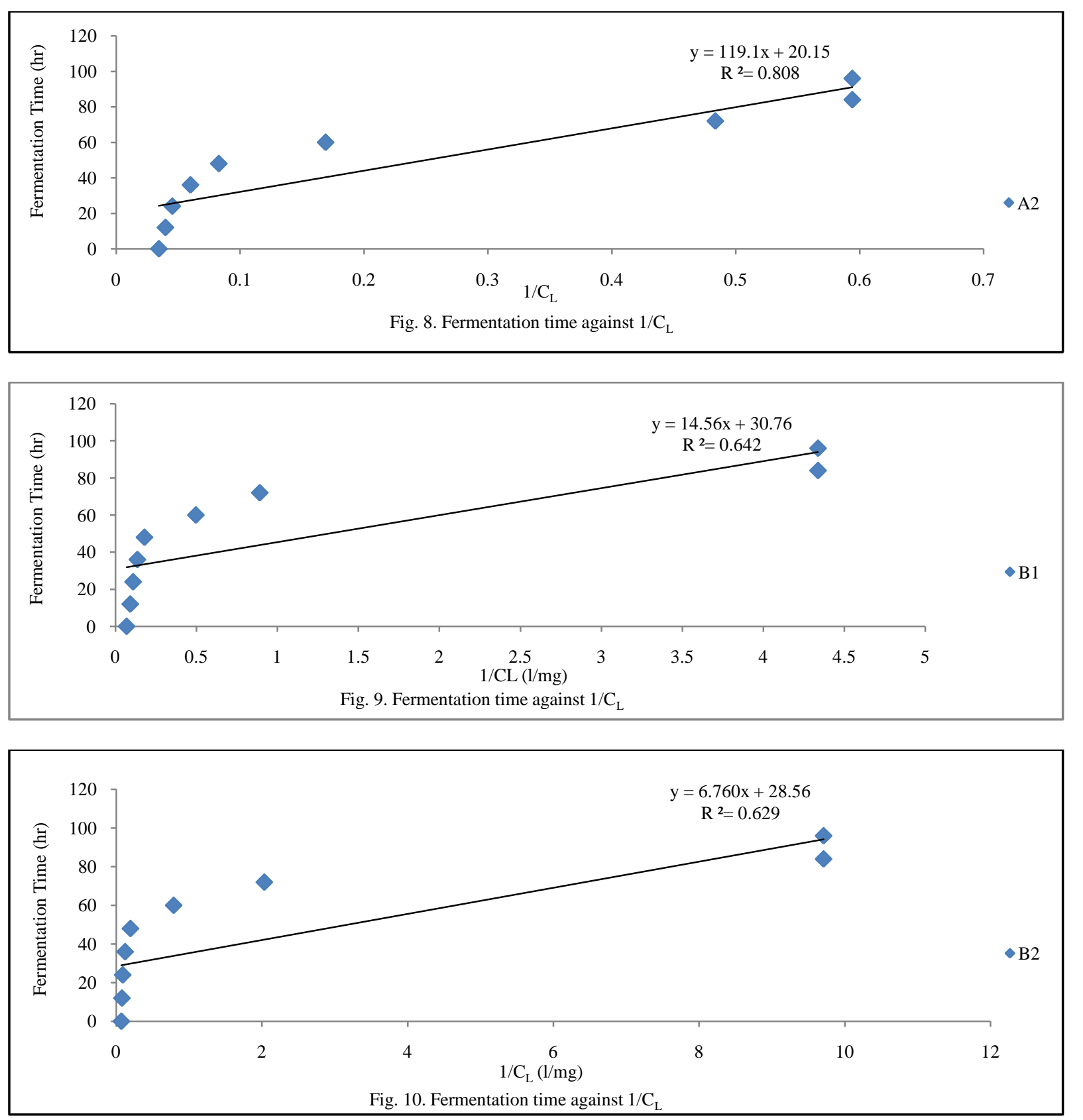

The concentration of $2,3-\mathrm{BD}$ production $10.626 \mathrm{~g} / \mathrm{l}$, $17.788 \mathrm{~g} / \mathrm{l}, 4.234 \mathrm{~g} / \mathrm{l}$ and $8.832 \mathrm{~g} / \mathrm{l}$ equivalent to $36.6 \% \mathrm{w} / \mathrm{w}$, $61.3 \% \mathrm{w} / \mathrm{w}, 29.2 \% \mathrm{w} / \mathrm{w}$ and $60.9 \% \mathrm{w} / \mathrm{w}$ of lactose utilization for $A_{1}, A_{2}, B_{1}$ and $B_{2}$ respectively were obtained at the optimum $\mathrm{pH}$ value. The results are found to be higher than that reported by Speckman (1988) [21] who used Bacillus polymyxa; Barette et al (1983) [19] who use Klebsiella pneumonia and Enterobacter aerogene but variation in the production of 2, 3-BD associated with variation in initial concentration of the cheese whey and the lactose content of the cheese whey used; and Vishwakarma (2010) [14] who used Klebsiella oxytoca.

Table 3 shows that the estimated value of the yield coefficient of KP cells found in the $A_{2}$ and $B_{2}$ were higher than that of $A_{1}$ and $A_{2}$ respectively due to agitation and aeration condition of the samples. The value of the Monod's kinetics constant $\mathrm{k}_{\mathrm{s}}$ for $\mathrm{A}_{2}$ and $\mathrm{B}_{2}$ obtained in air-stirred batch reactors was lower than that of $A_{1}$ and $B_{1}$ respectively in unaerated reactors. $\mathrm{k}_{\mathrm{s}}$ measure the metabolic activities of the Klebsiella pneumonia. Low value of $\mathrm{k}_{\mathrm{s}}$ indicates that Klebsiella pneumonia have a high affinity for the lactose utilization but it does not means that degradation of lactose and production of 2, 3-BD were not favoured. Though, high value of $k_{s}$ for $A_{1}$ and $A_{2}$ than $B_{1}$ and $B_{2}$ respectively cannot only justify that the kinetics of microbial degradation was not favourable. In contrast, the value of $\mu_{m}$ was found to be higher in $A_{2}$ and $B_{2}$ than $A_{1}$ and $B_{1}$ which indicates that agitation and aeration condition favoured the growth of KP cells in the cheese whey as a source of food and energy.

TABLE 3. EvaluATED KINETICS PARAMETERS

\begin{tabular}{lllll}
\hline Sample & $\mathrm{Y}_{\mathrm{BD} / \mathrm{L}}$ & $\mathrm{Y}_{\mathrm{X} / \mathrm{L}}$ & $\begin{array}{c}\mu_{\mathrm{m}} \\
\left(\mathrm{hr}^{-1}\right)\end{array}$ & $\begin{array}{c}\mathrm{K}_{\mathrm{S}} \\
(\mathrm{mg} / \mathrm{l})\end{array}$ \\
\hline $\mathrm{A}_{1}$ & 0.366 & 0.0666 & 0.0449 & 17.960 \\
$\mathrm{~A}_{2}$ & 0.613 & 0.1300 & 0.0496 & 5.9110 \\
$\mathrm{~B}_{1}$ & 0.292 & 0.0561 & 0.0325 & 0.4730 \\
$\mathrm{~B}_{2}$ & 0.609 & 0.1285 & 0.0350 & 0.2367 \\
\hline
\end{tabular}




\section{Conclusions}

Microbial production of 2,3-butanediol (2,3-BD), a value added chemical from cheese whey and bioremediation is a promising and attractive alternative for traditional chemical synthesis. The yield for 2,3-BD in cheese whey $\mathrm{A}_{2}, \mathrm{~B}_{2}, \mathrm{~A}_{1}$, and $\mathrm{B}_{1}$ obtained was $61.3 \% \mathrm{w} / \mathrm{w}, 60.9 \% \mathrm{w} / \mathrm{w}, 36.6 \% \mathrm{w} / \mathrm{w}$ and $29.2 \% \mathrm{w} / \mathrm{w}$ respectively. This signifies that agitation and aeration condition of Klebsiella pneumonia enhanced the yield of 2,3-BD concentration than a stationary and unaerated condition irrespective of the concentration of the lactose utilization in the cheese whey based on quantified kinetics parameters. The higher concentration of the Lactose utilization also favoured the production of 2,3-BD in this study and provides kinetics insight in the biodegradation of COD threat posed by cheese whey.

\section{REFERENCES}

[1] J-L. Audic, B. Chaufer, and G. Daufin. Non-Food Applications of Milk Components And Dairy Co-Products: A review. J. EDP Sciences, Lait 83(2003) 417-438. www.edpsciences.org

[2] K. V. Rajeshwari, M. Balakrishnan, A. Kansal, L. Kusum, and V. V. N. Kishore (2000). State-of-the-art of anaerobic digestion technology for industrial wastewater treatment', Renewable and Sustainable Energy Reviews, 4: 135-156.

[3] H. Lee, M. Song, and S. Hwang (2003). Optimizing bioconversion of deproteinated cheese whey to mycelia of Ganoderma luciderm. Process Biochem., 38: 1685-1693.

[4] S. S. Marwaha, and J. F. Kennedy (1988), Review: whey pollution problem and potential utilization. Intl. J. Food Sci. Technol., 23: 323-336.

[5] A. J. Mawson (1994), Bioconversions for whey utilization and waste abatement. Biores. Technol., 47: 195-203.

[6] S. P. Panesar, J. F. Kennedy, C. J. Knill, and M. Kosseva (2010, Jan.-Feb.). Production of L (+) Lactic Acid using Lactobacillus casei from Whey. Braz. Arch. Biol. Technol. 53(1): 219-226.

[7] R. D. Tyagi, D. Kluepfel, and D. Couilard. Bioconversion of cheese whey to organic acids. In: Martin, A. M., editor. Bioconversion of waste materials to industrial products. London; Appl. Sc. 1991, pp. 313-333

[8] J. Rivas, A. R. Prazeres, F. Carvalho, and F. Beltrán (2010). Treatment of cheese whey wastewater: combined coagulation-flocculation and aerobic biodegradation. J Agric Food Chem. 58(13): 7871-7877.

[9] E. W. J. Van Niel, K. Hofvendahl, and B. Hahn-Hägerdal, (2002). Formation and conversion of oxygen metabolites by Lactococcus lactis subsp. lactis ATCC 19435 under different growth conditions, Appl. Environ. Microbiol. 68: 4350-4356.

[10] J. Kim, C. Lee, S. G. Shin, and S. Hwang. Correlation of microbial mass with ATP and DNA concentrations in acidogenesis of whey permeate. Biodegradation, 2008, 19: 187-195
[11] A. O. Büyükkileci, and S. Harsa, (2004) Batch production of L(+) lactic acid from whey by Lactobacillus casei (NRRL B-441), J. Chem. Technol. Biotechnol. Vol.79, pp. 1036-1040.

[12] C. J. B. De Lima,, L. F. Coelho and J. Contiero (2010). The Use of Response Surface Methodology in Optimization of Lactic Acid Production: Focus on Medium Supplementation, Temperature and $\mathrm{pH}$ Control: Lactic Acid Production Optimization. Food Technol. Biotechnol. 48 (2): 175-181.

[13] C. Chih-Ching (2008). Taurine serves as sole source of nitrogen for aerobic and anaerobic growth by Klebsiella sp. World J Microbiol Biotechnol., 24: 895-898.

[14] S. Vishwakarma (2010, August). Countercurrent Extraction of 2,3-Butanediol. International Journal of Chemical Engineering and Applications, 1(2):147-150.

[15] E. L. Barrett, E. B. Collins, B. J. Hall, and S. H. Matoi (1983) Production of 2, 3-butylene glycol from whey by Klebsiella pneumoniae and Enterobacter aerogenes. J. Dairy Sci. 66: 2507-2514.

[16] N. B. Jansen, M. C. Flickinger, and G. T. Tsao (1984). Production of 2,3-butanediol from D-xylose by Klebsiella oxytoca ATCC 8724 Biotechnol. Bioeng. 26: 362-369.

[17] E. K. C. Yu, N. Levitin, and J. N. Sadler (1982). Production of 2,3-butanediol by Klebsiella pneumoniae grown on acid hydrolyzed wood hemicellulose. Biotechnol. Lett. 4: 741-746.

[18] V. M. Laube, D. Groleau, and S. M. Martin (1984). 2,3- Butanediol production from xylose and other hemicellulosic components by Bacillus polymyxa. Biotechnol. Lett. 6: 257-262.

[19] R. A. Speckman, and E. B. Collins (1982, May). Microbial production of 2,3-butylene glycol from cheese whey. Appl. Environ. Microbiol. 43(5): 1216-1218

[20] P. Desnuelle, and M. Naudet (1945). Analytical methods for bacteria fermentations, National Research Council of Canada (publication no. 2952), Saskatoon, Saskatchewan. 2nd rev., p. 37-38.

[21] D. H. Mallonee and R.A. Speckman (1988, Jan.). Development of a Mutant Strain of Bacillus polymyxa Showing Enhanced Production of 2,3-Butanediol. Applied and Environmental Microbiology, 54(1): $168-171$.

[22] A. Khanafari, A. A. Sepahei, and M. Mogharab (2006). Production and Recovery of Poly-B-Hydroxybutyrate From Whey Degradation by Azotobacter. Iran. J. Environ. Health. Sci. Eng., 3(3): 193-198.

[23] A. Khanafari and A. A. Sepahei (2007). Alginate Biopolymer Production by Azotobacter Chroococcumfrom Whey Degradation, Int J. Environ. Sci. Tech., 4 (4): 427-432

[24] M. A. Otero-Rambla and G. S. Laria. Batch propagation of Kluyveromyces sp Yeast in Whey. Institute Cubano de Investgaciones de los Derivados de la Cana de Azucar, 2008, pp.14-20.

[25] M. Akinobu, K. Yoshinori and O. Hajine (1992). Microbial Production of Optically active 1,3-Butanediol from 4-hydroxy-2-butanone. Bioscience, Biotechnology and Biochemistry, Vol. 57, No.2, pp.348-349.

[26] C. N. Owabor, S. E. Agarry and T. O. Azeez (2010, May) Development of a Transport Model for the Microbial Degradation of Polycyclic Aromatic Hydrocarbons in a Saturated Porous Medium. Journal of the Nigerian Association of Mathematical Physics. 16:317-324

[27] O. Levenspiel, Chemical Reaction Engneering. 3rd ed, New York: John Wiley and Sons Inc., 2002, pp.13- 641. 